\title{
Shakespeare y la sífilis
}

\section{Shakespeare and syphilis}

\section{Horacio Rolando Soria ${ }^{1}$ y Sergio Carbia ${ }^{2}$}

\author{
1 Profesor Regular Adjunto \\ 2 Docente Adscripto en Dermatología \\ Universidad de Buenos Aires, Ciudad Autónoma de Buenos \\ Aires, Argentina
}

Contacto del autor: Horacio Rolando Soria

E-mail:hrsoria64@gmail.com

Fecha de trabajo recibido: $7 / 8 / 2019$

Fecha de trabajo aceptado: 10/10/2019

Conflicto de interés: los autores declaran que no existe conflicto de interés.

Dermatol. Argent. 2020, 26 (1): 47-48
¡Hündete en tierra y sucumba Atenas! ;Madres de familia, haceos impúdicas! ¡Conviértete a la corrupción general, joven virginidad, y hazlo a la vista de tus padres! ¡Servidora, ve al lecho de tu amo, que tu ama está en el burdel! ¡Piedad y temor, religión para los dioses, paz, justicia, verdad, respeto doméstico, reposo nocturno, vecindario bueno, instrucción, modales, misterios, profesiones, jerarquias, observancias, costumbres, leyes, confundios con lo contrario, y reine la confusión doquiera! ¡Peste contagiosa para el hombre, amontónense tus fiebres poderosas e infecciosas sobre Atenas, madura ya para la ruina! ¡Fría ciática, deja tullidos a nuestros senadores, y que sus miembros rechinen como sus costumbres! ¡Lujuria y libertinaje, deslizaos por el espiritu de la médula de nuestra juventud para que pueda luchar contra la corriente de la virtud y anegarse en la podredumbre! jSarnas y pústulas, sembrad vuestros gérmenes en los pechos atenienses, para que su conjunto sea una lepra general! 'infecte el aliento al aliento, con el fin de que su trato, como su amistad, se haga venenoso! ¡No quiero soportar de ti sino la pobreza, ciudad detestable!

\section{WILLIAM SHAKESPEARE (INGLATERRA, 1564-1616)}

El doctor en Filología inglesa Vicent Montalt comenta: "William Shakespeare revolucionó el modo de hacer teatro. El dramaturgo tenía amplios conocimientos de ciencia y medicina, que usaba como anclaje fundamental para entretejer los ámbitos médico y político que tantas veces se han interpretado sobre un escenario". En tanto, Harold Bloom refiere: "Fue más allá de todo precedente e inventó lo humano tal como lo seguimos conociendo".

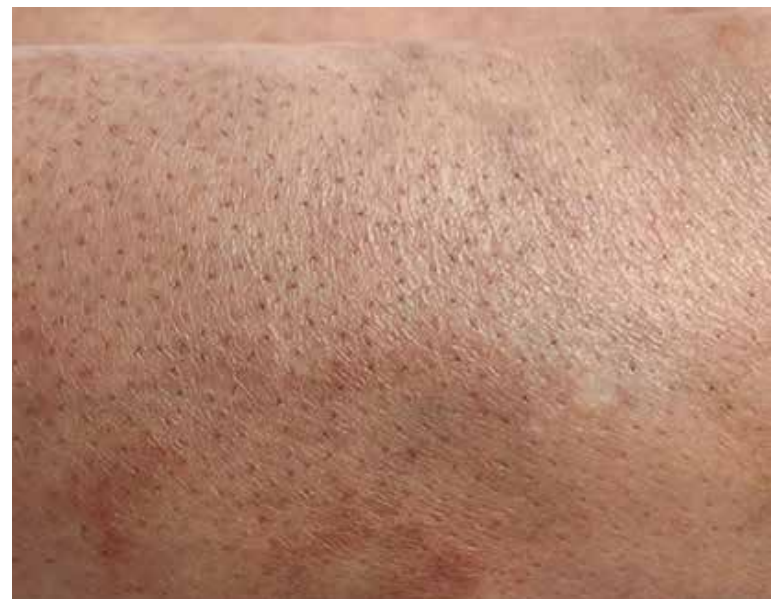

William Shakespeare está enterrado en la Holy Trinity Church de Stratford-upon-Avon, bajo un epitafio que dice: "Buen amigo, por Jesús, abstente de cavar en el polvo aquí encerrado. Bendito sea el hombre que respete estas piedras y maldito el que remueva mis huesos".

Uno de los aspectos trascendentales de su obra es la descripción, quizá metafórica -como algunos autores especulan- de magníficas exposiciones nosológicas, donde la dermatología no ha estado ausente.

Sus obras Enrique IV, Enrique V, Sueño de una noche de verano, Trabajos de amor perdidos y Medida por medi$d a$ son una pequeña parte de su extensa producción, en las que se citan otras entidades dermatológicas, además de las enfermedades venéreas.

El presente trabajo, escrito hacia 1607 o 1608, describe la vida de Timón de Atenas, ciudad donde se desarrollan las acciones. Timón es un caballero muy rico 
y por su casa pasa todo tipo de personas que se acercan a pedirle dinero. Como ve desaparecer su fortuna y los que lo adoraban lo abandonan, se retira a una caverna y, al cavar en busca de raíces con las cuales alimentarse, encuentra un tesoro. Se lo da a Alcibíades, que también detestaba a los atenienses por haber prescindido de sus servicios, quien lo utiliza para pagar a los soldados destinados a destruir la ciudad y a prostitutas para que contagien sexualmente a la juventud de Atenas. Lo sorprendente de esta obra, que satiriza la ingratitud humana y las costumbres de la época, es el uso de distintas expresiones relacionadas con enfermedades venéreas como lepra blanco-grisácea (hoar leprosy), así llamada porque formaba costras blanquecinas en la piel, donde hoar (ho:) es homófono de whore (ho:), "puta", lo que al aceptar la versión inglesa correspondería a "lepra de putas".

\section{BIBLIOGRAFÍA}

Shakespeare W. Junto a los muros de Atenas. Acto IV, Escena 1. En: Timón de Atenas. Disponible en: 131615.pdf- http://biblioteca.org. ar/libros/131615.pdf

\section{DERMATÓLOGOS JÓVENES}

\section{Elección múltiple. LESIONES PURPÚRICAS EN LOS MIEMBROS INFERIORES / Respuestas}

\section{Respuestas correctas: 1) ( ; 2) E; 3) D; 4) B}

Las dermatosis purpúricas pigmentarias (DPP) son un grupo de lesiones cutáneas crónicas y recurrentes. Se caracterizan por petequias y/o púrpura y máculas marrón-anaranjadas pigmentarias que se localizan principalmente en las extremidades inferiores

Se clasifican en seis grupos según el patrón clínico: máculas purpúricas de color marrón rojizo 0 petequias del tamaño de una cabeza de alfiler en la enfermedad de Schamberg (DPP progresiva); parches o placas anulares con telangiectasias y petequias en los bordes en la púrpura anular telangiectoide (enfermedad de Majocchi); parches o placas liquenoides de color marrón dorado en el liquen aureus; pápulas y placas purpúricas liquenoides poligonales o redondas en la dermatosis liquenoide purpúrica pigmentada de Gougerot y Blum; máculas, pápulas o placas purpúricas escamosas y pruriginosas en la púrpura pruriginosa; máculas y parches purpúricos eccematosos en la púrpura de tipo eccematoide de Doucas-Kapetanakis (púrpura de tipo eccematoide). Aunque estos patrones representan las diferentes características morfológicas, la histopatología, el tratamiento y el pronóstico de todas las entidades son similares.

Se desconoce la causa de las DPP, pero se ha sugerido que varias situaciones comórbidas o medicamentos pueden estar asociados, como insuficiencia venosa crónica, diabetes mellitus, hiperlipidemia, fragilidad capilar e hipersensibilidad a fármacos ( $\mathrm{pa}$ racetamol, aspirina, antiinflamatorios no esteroides, diuréticos, dipiridamol, bezafibrato, etc.). Otras causas incluyen alergia de contacto a metales o colorantes, ropa e ingesta de alcohol.

El diagnóstico suele hacerse clínicamente, aunque en algunas circunstancias es necesaria la histopatología para diferenciarlo de vasculitis u otras enfermedades inflamatorias. Los hallazgos histológicos varían desde un infiltrado inflamatorio linfocítico perivascular, extravasación de eritrocitos y depósito de hemosiderina focal, hasta la infiltración liquenoide densa, espongiosis o infiltración granulomatosa.

La enfermedad tiene un curso benigno, aunque las DPP son cuadros crónicos, con exacerbaciones recurrentes. En términos de tratamiento, ninguna terapia única o combinada es superior a otra. Los tratamientos destinados a mejorar los factores etiológicos relacionados (p. ej., insuficiencia venosa crónica) pueden ayudar en algunos casos. También se recomienda la aplicación de emolientes y humectantes.

Basados en series y publicaciones de casos, los tratamientos utilizados con resultados terapéuticos satisfactorios son: en lo que respecta al tratamiento tópico, el uso de esteroides locales para reducir el prurito, 0 inhibidores de la calcineurina. Entre los tratamientos sistémicos, los antihistamínicos orales también se han utilizado como una medida de apoyo para controlar el prurito, se encuentra la terapia con flavonoides y altas dosis de ácido ascórbico (su mecanismo de acción está relacionado con una mejora de las funciones de la barrera endotelial vascular, a través de un aumento en la síntesis de colágeno). Otro agente que ocasionalmente ha mostrado resultados prometedores es la pentoxifilina. Por último, los informes que indican un efecto beneficioso de la fototerapia en el tratamiento de las DPP están presentes en la literatura médica.

\section{BIBLIOGRAFÍA}

- Kim DH, Seo SH, Ahn HH, Kye YC, et ál. Characteristics and clinical manifestations of pigmented purpuric dermatosis. Ann Dermatol 2015;27:404-410.

- Huang Y-K, Lin C-K, Wu Y-H. The pathological spectrum and clinical correlation of pigmented purpuric dermatosis- A restrospective review of 107 cases. J Cutan Pathol 2018;45:325-332.

- Plachouri K-M, Florou V, Georgiou S. Therapeutic strategies for pigmented purpuric dermatoses: a systematic literature review. J Dermatolog Treat 2019;30:105-109. 